\title{
The impact of a call centre on communication in a programme and its projects
}

\author{
Taryn Jabe Bond-Barnard ${ }^{a \star}$, Herman Steyn ${ }^{a}$, Inger Fabris-Rotelli ${ }^{b}$ \\ ${ }^{a}$ Graduate School of Technology Management, University of Pretoria, South Africa \\ ${ }^{\mathrm{b}}$ Department of Statistics, University of Pretoria, South Africa
}

${ }^{*}$ Corresponding author. Tel.: +27 836312274; fax: +27 124520456

E-mail addresses: tarynjanebond@gmail.com, taryn@acall.co.za

(T.J. Bond-Barnard).

\section{A b s t r a c t}

Call centres are increasingly being utilised in public sector programmes to facilitate and manage communication between numerous stakeholders. Yet, the impact of call centres on projects has not been investigated. This paper reports on a survey with 92 respondents that assessed the impact of a call centre for a repair and maintenance programme. An empirically verified model is presented to illustrate the relationship between call centre communication and project performance. A balance of frequent informal and formal communication is shown to reduce mistrust and conflict of interest resulting from each party trying to maximise his respective economic position in the principal-agency relationship. The data provides evidence that a call centre improves the communication, collaboration and trust in project principal-agency relationships which, in turn, is perceived to contribute to project performance.

Keywords: Communication, Project Communication Management, Call centres, PrincipalAgency Theory, Project Performance 


\section{Introduction}

It is clear that programme management has the potential to make a significant contribution to integrated service delivery by the South African government; programmes may act as an ideal vehicle through which various government departments could coordinate their efforts (de Coning \& Günther, 2009). However de Coning and Günther (2009) state that a number of organisational, human resources, financial and system challenges exist for officials from different departments to act on the same programme teams across organisational boundaries. These challenges can be narrowed down to a need for effective project communication across organisational boundaries and a greater focus on stakeholder satisfaction.

Literature confirms that communication is an essential prerequisite to successful projectbased management (Dainty et al., 2006). However Lehmann (2009) and Dainty et al. (2006) agree that communication is paid scant attention in project management even though there was an increased interest in project communication and information management research from 1960 to 1999 (Crawford et al., 2005; Kloppenborg \& Opfer, 2002). The lack of communication literature in project management has resulted in communication being cited as a primary cause of project failures on numerous occasions (Dainty et al., 2006; OGC in Shehu \& Akintoye, 2010; Gillpatrick cited in Pinto \& Pinto, 1990; Pinto \& Pinto, 1990; Souder, 1981)

It has already been established in literature that frequent communication improves stakeholder satisfaction (Shao \& Müller, 2010) and project member collaboration and trust (Müller, 2003). Communication has also been identified as one of the most important contributors to project success. Therefore it is essential that communication in the project management body of knowledge be expanded to include 'how' to communicate effectively in projects and programmes rather than just stating 'why' communication is important. 
A project usually involves a number of stakeholders including; the project owner/client, project manager, contractor and beneficiaries. The project manager acts on behalf of the client and manages the project delivery on a day-to-day basis (Turner \& Müller, 2004). Furthermore, the contractor is often instructed to act on behalf of the project manager and carry out the project work.

As in other delegated tasks, the client and project manager are in a principal-agency relationship (Bergen et al., 1992; Jensen, 2000). Similarly the project manager and any subcontractor are also in a principal-agency relationship. If the aim of both parties is to maximise their respective economic positions, then it is possible that the agent will not always act in the best interests of the principal. Thus principal-agency theory explains the potential for a conflict of interest to arise between the principal and the agent because, as Jensen (2000) states, people will not act in the best interest of others (their principals) to the exclusion of their own preferences.

However, Turner and Müller (2004) state that communication between principal and agent reduces the mistrust and conflict of interest between them and thus improve project performance. Furthermore, it has been established that the communication needs of project principals and agents are best met by a mixture of formal and informal communication, and of written and verbal communication (Turner and Müller, 2004).

Literature advises project managers to be aware that project stakeholders rely on several communication channels, which includes not only face-to-face and written media, but also telephonic/verbal communication (Müller, 2003). Project managers on the other hand have a strong preference for verbal communication over other forms (Mintzberg et al., 1976). These communication type preferences and the fact that the project or programme manager is at the centre of the project delivery process is a real communication management challenge. He or she must maintain a range of complex communication channels with different types of 
organisations (Dainty et al., 2006); while still facilitating and managing frequent communication with the project members and stakeholders, to ensure project success.

As a result of principal-agency theory it is common for project members to manipulate information in their favour if unexpected problems occur (Loosemore, 2000). The manipulation of information in closed communication systems erodes the trust which is necessary for effective teamwork (Dainty et al., 2006).

Based on the numerous communication channels present in a project and the possibility of manipulation of information in project principal-agency relationships; it stands to reason that the utilisation of a programme call centre can mitigate these issues. The programme call centre which was investigated for the purposes of this paper acts as an objective third party communication hub responsible for facilitating and managing the communication of project issues to all stakeholders on behalf of the project manager. This paper addresses the following questions:

- Does a programme call centre improve the frequency of communication and collaboration in the principal-agent relationships present in a project?

- Does the project communication provided by the call centre reduce project 'surprises/issues' and subsequently improve project team trust?

- Does a programme call centre improve the management of project communication and the perceived performance of the project?

Furthermore, some of Turner and Müller's (2004) findings regarding the frequency, type and effect of communication on the level of trust in principal-agency relationships are tested in this paper. This was done by incorporating said findings into a proposed model of call centre facilitated communication and project performance. The model therefore illustrates the role that a project call centre can play in improving communication, collaboration and trust in a 
project which is perceived to contribute to improved project and programme performance. This model is then tested by means of a survey to determine the impact of a call centre on communication in a programme and its projects.

\subsection{The National Repair and Maintenance Programme}

Shehu and Akintoye (2010) define programme management as an integrated, structuredframework to co-ordinate, align, and allocate resources, as well as plan, execute and manage a portfolio of construction projects simultaneously to achieve optimum benefits that would not have been realised had the projects been managed separately. In line with this definition, the South African Department of Public Works (DPW) repair and maintenance programme aims to alleviate the repair and maintenance backlog at approximately 600 national government facilities. Communication regarding reactive maintenance (or 'breakdowns') at these facilities which is facilitated, monitored and managed by a central call centre, is the focus of this paper.

The DPW is tasked with promoting commercial attitudes within the public sector regarding the efficiency of service delivery programmes and facilitating the service delivery of other national government departments through the provision and management of public sector infrastructure. DPW implemented the programme in 2000, with the aim of repairing public sector infrastructure to a functional condition and maintaining such infrastructure so that it could be used by the other departments for its intended purpose (DPW, 2004). It was decided that a call centre would facilitate and manage the communication, documentation and performance reporting of all reactive breakdown repair and maintenance work for all projects involved, to improve the service delivery to user department representatives. The call centre communicates with the various project teams on a regular basis. The project team referred to in this study consists of:

- The client, DPW, and the user department representatives at the facility; 
- The project manager who oversees several projects, usually at different facilities;

- The consulting engineer (consultant) who manages the project on a day-to-day basis and instructs the contractor;

- The contractor responsible for performing maintenance and attending to breakdown repairs at the facility.

The call centre process commences when the client at the facility phones a specific number to log a breakdown, which could be anything from interrupted water supply at a prison to damage of a section of fencing at a border post. The call centre logs the details of the breakdown and provides the caller with a unique reference number. The breakdown is reported to the consulting engineer, firstly by telephone (to confirm the priority of the breakdown) and secondly by fax/email. Upon the consultant's consent the fax/email is also sent to the contractor. Hereafter, it remains the duty of the consultant to verbally notify the contractor of the breakdown.

Once the contractor has attended to the breakdown, he notifies the consultant. Provided that the consultant is satisfied with the quality of the contractor's repair work or response to the breakdown, the consultant notifies the call centre that the breakdown has been attended to. The call centre then follows up the resolved breakdown by contacting the party who originally logged the breakdown and enquires whether the issue was satisfactorily resolved.

\subsection{Objectives}

The call centre is responsible for facilitating and managing the reactive breakdown repair and maintenance communication between all project participants (including both principalagency relationships). The aim of this paper is to verify if call centre communication negates the effects of principal-agency theory in a repair and maintenance programme and its projects. Furthermore, this paper investigates whether an increase in project communication 
(facilitated by a call centre) improves the communication, collaboration and trust between principals and agents and consequently their perception of the project's performance (quality of project deliverables and customer satisfaction) on a set of 196 of the projects. The impact of a call centre on project communication management is therefore empirically established.

This aim was achieved by investigating the following propositions for the projects under consideration:

- The convenience of a call centre improves the frequency of formal and informal communication between the principals and the agents in a project;

- An increase in principal-agent communication increases the parties' perception of collaboration between them;

- An increase in call centre communication increases the avoidance of surprises, and leads to improvement in the trust between the principal and the agent;

- The call centre significantly improves the management of communication in the projects;

- The project communication facilitated and managed by the call centre improves the perceived performance of the projects and service delivery of the national programme.

\subsection{Literature review}

Communication can be viewed as a metaphorical 'pipeline' along which information is transferred from one person to another (Axely, 1984). Thus the purpose of communication is the transfer of information between people, involving a person or entity sending out a message and another receiving and successful understanding the message in response (Torrington \& Hall, 1998).

Consequently, many communication theorists have drawn upon the simple analogy between the human communication process and the electronic telecommunications process where 
information is sent from transmitter to receiver through a channel medium, which is mediated by noise and controlled by a feedback loop (Shannon, 1948; Weaver, 1949; Wiener, 1950; Baguley, 1994; Torrington et al., 1995; Emmitt and Gorse, 2003). More recently the social and psychological perspectives of the late twentieth century have also contributed to communication theory, however there is no coherent body of knowledge but rather a set of fairly disparate areas and subfields (Dainty et al., 2006).

The role of the project management function is to manage the systems that relate to the features of uniqueness, novelty and transience which define the term 'project'. These systems are namely the scope of work, the project organisation, the quality, the cost and the duration of the project. Communication is an essential ingredient of all of these managerial requirements and must be viewed as the essential prerequisite to successful project-based management (Dainty et al., 2006).

The development of literature relating to communication in project management has virtually ignored the "new communication" proposals put forward by researchers such as Bateson, Birdwhistell, Goffman, Hall, Jackson or Watzlawick (1954 to the present) (cited in Lehmann, 2009). As a result, the most current variations on project communication contain elements of systematic communication (Mucchielli cited in Lehmann, 2009), translator communication (Callon et Latour, 1986) or network communication (Stohl, 1995) to quote but a few. Lehmann (2009) and Dainty et al. (2006) agree that communication is paid scant attention in project management. Historically, research into project management has emphasized efficiency rather than behavioural or interpersonal factors (Munns \& Bjeirmi, 1996).

Studies have been conducted on the state of current project management research in an attempt to determine trends and predictions for the future. Findings indicated that since the 1990's there has been an increasing interest in research related to communication (Crawford et al., 2005; Kloppenborg \& Opfer, 2002). Kloppenborg and Opfer (2002) indicated that 
government project management trends from 1960 through 1990 included an increased emphasis on stakeholder identification and management, and an increased emphasis on communications and communications planning.

An investigation of trends in project management journals (Crawford et al., 2005) also revealed that there was a growing interest in relationship management topics. Topics relating to information and communication management, reporting, benefits management, document management, teambuilding and development were all mentioned as popular topics in the International Journal of Project Management (IJPM) from 1994 through 1998 and in the Project Management Journal (PMJ) from 1999 through 2003. Relationship management is consistently reported as either being of significance or increasingly significant from 1983 through 2003 in both the IJPM and the PMJ. It can be deducted from these findings that there should be an increased focus on communications planning, particularly as it relates to stakeholder management and communications (Kloppenborg \& Opfer, 2002). This need serves as a motivation to investigate whether a call centre can be used to improve the project communication in projects and programmes.

\subsection{Communication, collaboration and trust}

How does one go about communicating effectively in a project or programme? Torrington and Hall (1998) found that messages are more successfully conveyed if a variety of media such as verbal, non-verbal, written, audio-visual or electronic are used. Gorse et al. (1999) built on this 'notion' by exploring a range of media from informal face-to-face meetings to formal methods such as letter, fax and email; their results showed that the former was perceived to be the most effective medium of communication. Gorse et al.'s findings are supported by Carlsson et al. (2001) who added that verbal exchanges in the form of telephone conversations or meetings form the cornerstone of interaction within the 
construction industry. Moreover it had already been established by Mintzberg et al. (1976) that project managers have a strong preference for verbal communication over other forms.

More recently Lewis (2001) and Weiss and Wysocki (2000) added that knowing how to use feedback properly and being equipped with a good information system appropriate for the project is also important for communicating "well". It has been determined that the interplay of situation-appropriate teamwork communication, synchronicity and coordination increases collaboration which predicts team performance (Chiocchio et al. cited in Chiocchio et al., 2011; Kozlowski \& Bell, 2003; lePine et al., 2008). Furthermore trust can be defined as a function of the predictability and expectations of others' behaviours or a belief in others' competencies, which affects performance through activation of cooperation (Tyler, 2003) or other collaborative processes (Chiocchio et al., 2011). In this paper it is investigated whether the frequent informal and formal communication, facilitated by a call centre, improves the communication, collaboration and trust in the project's principal-agency relationships which, in turn, has been linked to high project performance (Chen et al., 2010; Webber, 2008; Turner \& Müller, 2004).

Project management literature frequently outlines the importance of good communication for success in projects. However, most research is focused on the effect of the amount of communication, channels of communication, effective project networks, forms and purposes for communication (Katz, 1982; Katz \& Tushman, 1979; Pinto \& Pinto, 1990). The frequency, content and types of communication as well as communication formality are discussed in greater detail below. 


\subsubsection{The frequency of project communication}

Communication frequency refers to the number and timing of the project managers' communication with the client (Turner \& Müller, 2004). Müller (2003) showed that project managers and their clients differentiate between three communication frequencies:

- Continuous communication, daily or at least weekly interaction - this is the most preferred frequency across all projects.

- Fixed interval communication, at bi-weekly or monthly intervals - this frequency is most preferred in high performing projects with high levels of collaboration.

- Variable interval communication, at milestone or project phase end - this is occasionally preferred in order to reduce communication efforts in projects. It can lead to a decrease in collaboration and subsequently project failure.

However, it has been found that regular, daily or weekly communication gives the client the greatest comfort that they are being kept informed of project progress and of the decisions being taken by the project manager on their behalf. It is frequent communication that builds the greatest trust in the project manager (Turner \& Müller, 2004).

\subsubsection{The content of project communication}

Project teams use a variety of contents and media for their communication with each other and the client. Müller (2001) showed that the content of project communication falls into one or more of the categories below:

- $\quad$ Status and achievements;

- $\quad$ Changes to the project;

- Issues and open items;

- Next steps in the project;

- Quality and progress measures;

- Trends in the project. 
This paper discusses the utilisation of a call centre to facilitate and manage the communication of issues and open items as well as quality and progress measures relating to projects.

\subsubsection{Types of project communication}

According to Johnson et al. in Turner and Müller (2004) formal reports are perceived by clients as the most credible source of information. In contrast, Turner and Müller (2004) state that authors from industry prefer interactive media over formal written reports even though it has potential legal consequences. Müller (2003) establishes that communication contents and media are intertwined and cannot be separated. Turner and Müller (2004) distinguish between four different communication modes:

- Personal project reviews: face-to-face meetings with in-depth discussion of all the contents factors listed in 1.4.2;

- Project analysis: information on quality metrics and project trends, provided through all media (face-to-face, telephonic/verbal and written);

- Written status reports: written information about current status and achievements, issues, changes, next steps and other items needing communication. These items are potentially followed up through verbal (telephonic) or face-to-face communication;

- Verbal updates: brief and timely verbal updates inform the project manager on status and achievements, issues, changes and next steps.

Turner and Müller (2004) recommend that quick verbal updates be used in conjunction with formal written reports as this type, frequency and formality of communication is especially appreciated by project clients; they then feel reassured that they have the correct understanding of the formal written reports provided to them. Furthermore, Vaananen et al. (2010) state that personal relations are the main source for information for personnel who are conducting the actual work on the project. Written reports on their own cause ineffective 
communication by increasing the gap in the project manager's knowledge and the clients' understanding of the project's performance (Turner \& Müller, 2004). Contrarily, frequent face-to-face communication closes this knowledge gap and reassures the clients that they have a true picture of the project's progress; however this is not always possible where the project team is geographically dispersed (Harvey \& Griffith cited in Vaananen et al., 2010). In such instances frequent telephonic/verbal updates are the most effective form of communication in a project. In summary, there is need for a balance in formal and informal communication.

\subsubsection{Communication formality}

Formal communication takes place across official channels and provides the project manager and client with the information they require from each other. The PMI (2008) categorises reports and briefings as formal communication and ad-hoc conversations as informal communication. It is generally accepted that formal communication is regimented, deliberate and impersonal in nature as opposed to informal communication which is characterised by behavioural spontaneity, casualness and interpersonal familiarity (Morand, 1995). Furthermore, formal communication is perceived as slow in speed and high in accuracy while informal communication is perceived to be high in speed and low in accuracy (Mullins, 1999).

Müller (2003) states that the extent to which informal and formal communication is used, is determined by the frequency of interaction and the potential audience of the report. One-toone communication is more informal, promotes trust and knowledge building whereas oneto-many communication is more formal, creates mistrust and is controlled. If the main form of communication between the client and principal is infrequent and informal in nature, then the client's fear that the project manager is pursuing his own interests will be expressed as a desire for objective project data. This situation can be resolved by providing the client with 
reports containing the requested analytical data and also using verbal communication (telephone calls) to check that the client is satisfied with the credibility of the report contents (Müller \& Turner, 2007; Turner \& Müller, 2004).

\subsection{Call centres}

Call centres are defined as centralised, specialised operations for both inbound and outbound communication handling (Koh et al., 2005). References to call centres are frequently made in literature, yet there appears to be very little information regarding the utilisation of call centres in projects.

Call centres have been in existence for a number of decades, yet little has been reported on customer satisfaction with this mode of service delivery (Koh et al., 2005). Mitchell (1998), in fact argues that call centres might be the hub of successful strategies for client relationship management and could well be the fulcrum of organisations.

The adoption of web-based technologies by clients has received considerable attention in literature but researchers have neglected the field of service quality in call centre operations (Bennington, 2000). According to Prabhaker et al. in Bennington et al (2000), "the modern call has been around for about 50 years yet is as current as tomorrow". Prabhaker's "modern call" refers to the use of call centres as a means to improve a product or company's service quality. It is thus remarkable that, even though concerns have been expressed about customer satisfaction with call centre operations (Crome, 1998), empirical studies have been published only on staff dissatisfaction with call centres, rather than on client satisfaction (Bennington, 2000). Moreover, given that the use of call centres has increased by up to $50 \%$ per year (Crome in Bennington, 2000), and the world market for call centres is estimated to be $\$ 325$ billion U.S. (Burbury in Bennington, 2000), there is a significant opportunity for research in this area. 
It has been reported that knowledge management effort in call centres is scarce or almost nil. In a study conducted by Koh et al. (2005) knowledge management in call centres can be achieved by managing the five roles of knowledge (knowledge acquisition, knowledge utilisation, knowledge adaptation, knowledge distribution and knowledge generation) effectively. In most call centres, management effort is mainly focused on information management. Literature suggests that call centre operations are especially suited to information delivery, customer services and sales operations (Houlihan in Koh et al., 2005). However, the utilisation of call centres for information management and even knowledge management must still be investigated in the context of a project environment. This study explored the extent to which a call centre improved the communication, information management and customer satisfaction in a project.

\section{2. $P r \circ p \circ s$ e d M o d e I}

Research shows that the best project performance is obtained when there is high collaboration between the principal and the agent and medium levels of structure (Turner \& Müller, 2004). However, because of the principal-agency phenomenon, a high level of collaboration is not always the case. Two significant principal-agent relationships can be identified in the national programme referred to in this paper, namely the relationship between:

- $\quad$ The client (as principal) and the project manager/consultant (as agent) and

- $\quad$ the consultant (as principal) and the contractor (as agent)

Turner and Müller (2004) have shown that communication between the principal and the agent reduces the mistrust and conflict of interest between them and thus improve project performance. Furthermore, it has been established that the communication needs of project principals and agents are best met by a mixture of formal and informal communication, and of written and verbal communication (Turner and Müller, 2004). 
Frequent communication improves the collaboration between the project participants which, in turn, is a key condition for high performance in projects and essential for the development of trust. Turner and Müller (2004) state that frequent communication increases collaboration and leads to the avoidance of projects surprises or issues. The avoidance of project surprises has also been shown to improve collaboration. Research suggests that there is a direct correlation between high collaboration and trust in a project. Moreover, it has been found that trust usually exists where informal communication is used (Turner \& Müller, 2004).

The aim of the proposed model was to:

- Determine whether call centres can be used to facilitate effective communication to increase communication, collaboration and trust in a project, for improved project performance.

- Test the validity of the statements that Turner and Müller (2004) made regarding communication as a way of reducing the detrimental effects of principal-agency relationships in projects, by utilising a call centre.

The validity of the model developed from the findings of Turner and Müller (2004) was assessed by studying the perceived impact that the relevant call centre has on the projects where it is used as a communication hub for reactive breakdown repair and maintenance reporting and tracking. An extensive literature survey did not yield a suitable conceptual model for the investigation. Therefore, the model proposed in Figure 1, was developed. The model proposes that various interactions occur as a result of the project communication that is facilitated and managed by a call centre.

Quantitative surveys were developed to address the interactions depicted in Figure 1 as the purpose of the study was to test the validity of propositions formulated in previous qualitative studies rather than to explore new phenomena. A communication study was required to obtain evidence for the propositions and to establish the causation between the variables 


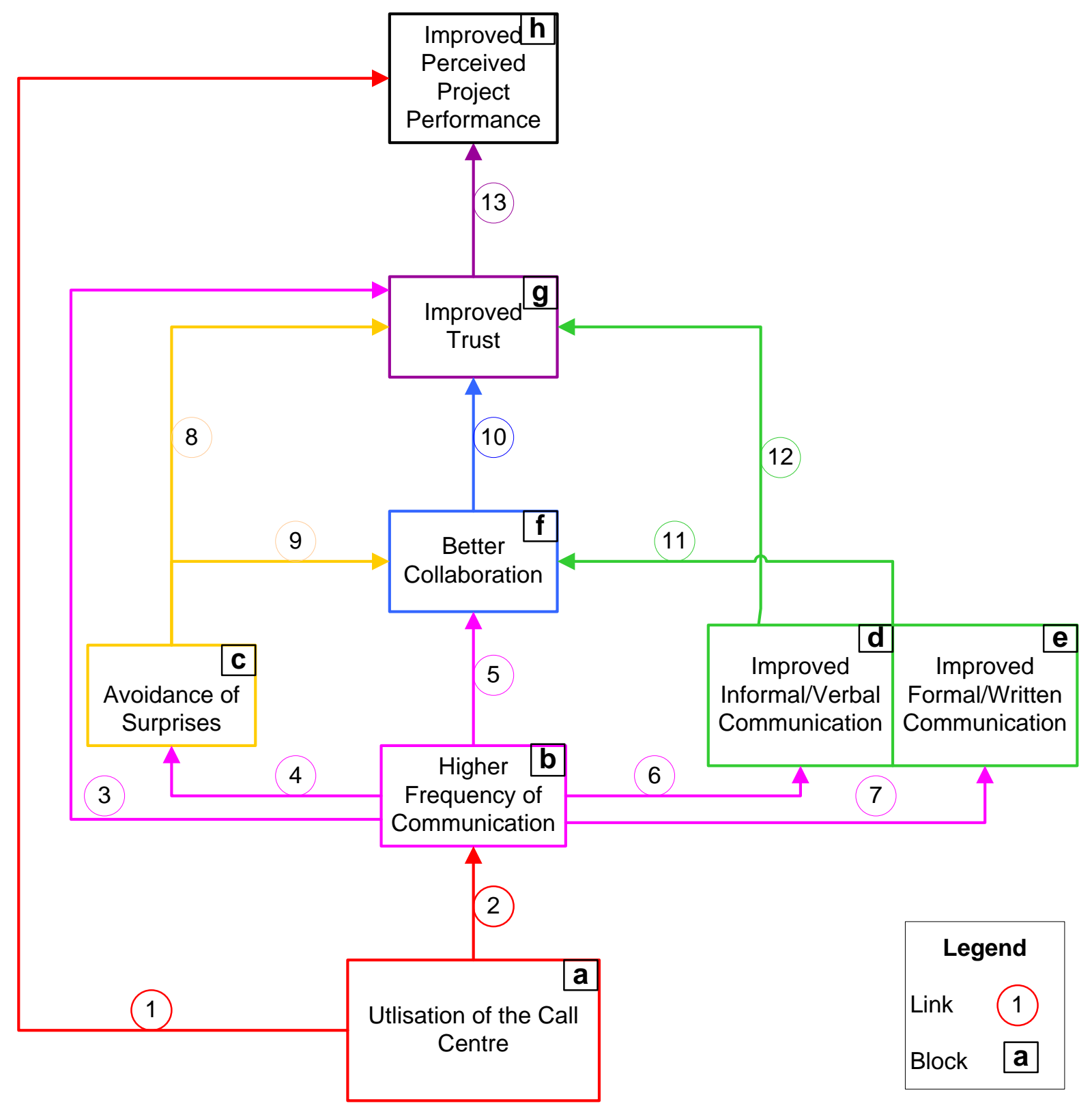

Figure 1. Call centre facilitated communication and project performance model.

proposed by the model. The surveys were used to determine the impact of the call centre communication type and frequency on the communication, collaboration and trust in the client-project manager/consultant and consultant-contractor principal-agent relationships for 196 projects. Three surveys were developed to address the unique interaction which each project member has with the call centre and with the rest of the project team. The surveys were conducted by mail and self-administered means to obtain representative data for the 
project managers/consultants, contractors and clients, to provide insight into the effectiveness of the programme call centre from three different user perspectives.

\section{Research Methodology}

A review of literature indicated that a need existed for the development of new and/or improved theories regarding the utilisation of call centres to facilitate and manage the communication in projects. A better understanding of the effect that call centre communication has on the principal-agency relationships in a project, and more specifically the effectiveness of the call centre in managing the communication of the repair and maintenance programme, was required. The model proposed in Figure 1, summarises Turner and Müller's (2004) findings on project communication as a means of reducing the problems associated with the principal-agency theory to achieve better project performance. The model also proposed additional characteristics of communication in projects such as the role of call centre communication in a project, the proposition that frequent call centre communication can improve project performance and that frequent call centre communication increases principal-agent communication. The proposed model provides a basis for the development of the research design and methodology to test the statements made by Turner and Müller (2004) and to determine the validity of the additional propositions regarding communication characteristics and interactions.

The approach for this study was to firstly assess the frequency with which the project team members communicate with the call centre and with each other and their perceived trust in the content of the communication they received from the call centre. Secondly, it was determined whether the project participants perceived an improvement in project team communication, collaboration, surprise avoidance, trust and project performance as a direct result of the frequent communication facilitated by the call centre. 
The repair and maintenance program referred to in this study consists of numerous projects where each project consists of a project manager, consultant and contractor. The research population consisted of the individual populations of the project members (i.e. project managers, consultants and contractors) associated with the 196 active projects registered on the programme call centre database. These three designations including that of 'client' were considered to be the units of analysis for the investigation. Furthermore, the project manager, consultant and contractor populations that are associated with the 196 active projects registered with the call centre served as the sample frame for this study. Census sampling was specifically selected for the consultant and contractor populations as the authors had access to these two populations whereas convenient sampling was used for the client group, with an unknown population (this is discussed in more detail below).

Based on observation, it was noted that the consultants often performed the duties of the project manager in addition to their own; therefore it was decided to combine these two groups into one group called 'project manager' for the purposes of the survey. The subpopulation for the project manager and contractor groups was reduced to unique samples only, as some participants were involved in more than one project and it was decided not to swamp or overwhelm these participants with surveys which might cause them to decide not answer at all. Consequently, the project manager and contractor populations were determined to be 194 and 134 respectively. The survey was distributed to the entire project manager and contractor population. Convenient sampling was employed for the client group as the size of the sub-population was unknown, it was cost effective and because the study had severe time constraints.

Three surveys were formulated to test the characteristics for the three different groups namely (a) clients, (b) the project managers and (c) contractors. The survey questions tested the perceived validity of the statements made by Turner and Müller (2004) regarding the communication and cooperation on projects between the principal and the agent and several 
questions were posed to all three groups for the purposes of comparison. As previously mentioned, the projects are characterised by two principal-agent relationships namely between the client and the project manager and between the project manager and the contractor.

A total of 194 project managers and 134 contractors received self-administered surveys whereas 40 clients received the survey by email, fax or in hard copy. The response rates for the various surveys were as follows:

- Project manager survey: 72 responses out of a population of 194 , however fourteen responses were identified as incomplete, therefore the response rate was 30\%;

- contractor survey: 24 responses out of a population of 134, however 12 responses were incomplete, therefore the response rate was $9 \%$

- client survey: 22 responses out of a sample group of 40 . There were no incomplete responses, therefore the response rate was $55 \%$

It is acknowledged that the response rates for the surveys are low due to non-response error and time constraints however; the responses received give a good indication as to the predominant perceptions of the various groups. A follow-up study is underway to investigate the relationships, which were derived from the first study, in greater detail.

Nominal sample data was obtained from the survey furthermore Likert type scales were used to express the participant's degree of agreement with the statements made. Firstly, each question was associated with a block in the proposed model and classified as either an independent or dependent variable. For example, the survey questions which were identified as independent variables for block F ('Better collaboration') in Table 1 were as follows: 
Table 1. The survey questions identified as independent variables for Block $F$ 'Better Collaboration'

\begin{tabular}{|l|l|}
\hline Group & Independent Variable Question \\
\hline \multirow{2}{*}{ manaject } & $\begin{array}{l}\text { Does the combination of telephone calls and faxes/reports that you receive from the RAMP Call } \\
\text { Centre improve the collaboration (teamwork) between you (the project manager) and the } \\
\text { contractor? }\end{array}$ \\
\cline { 2 - 3 } & $\begin{array}{l}\text { Does a higher frequency of RAMP Call Centre communication lead to better collaboration } \\
\text { (teamwork) between you and the other project team members? }\end{array}$ \\
\hline Contractors & $\begin{array}{l}\text { Does the combination of telephone calls and faxes/reports that you receive from the RAMP Call } \\
\text { Centre improve the collaboration between you (the contractor) and the project manager? }\end{array}$ \\
\cline { 2 - 3 } & $\begin{array}{l}\text { Does a higher frequency of RAMP Call Centre communication leads to better collaboration } \\
\text { (teamwork) between you and the other project team members? }\end{array}$ \\
\hline Clients & $\begin{array}{l}\text { Does a higher frequency of communication between the RAMP Call Centre and the project } \\
\text { team increase the level of collaboration/teamwork between the project team members? }\end{array}$ \\
\hline
\end{tabular}

Secondly, a chi-square test was done on the data collected for each survey question to determine if it was significant to the model or not. Thirdly, general linear models were used in conjunction with F-tests to determine whether an individual or combination of independent variables affected the dependent variables for the interactions proposed by the model. All the independent variables which were significant at at least a significance level of 0.1 were included to provide evidence for the interaction it represented in the model.

\section{4. $\quad R$ e $s u \mid t s$}

The model in Figure 1 depicts the relationship between project communication, facilitated by a call centre, and project performance. Descriptive statistics in the form of percentages are provided in sections 4 and 5 to support the findings of the study.

The survey provided evidence that the communication, facilitated by a call centre, reduced the mistrust and conflict of interest between the client and the project manager and between the project manager and the contractor of a repair and maintenance project. The project 
team members surveyed provided evidence that the proposed communication model was representative of the principal-agent relationship between the client and project manager and between the project manager and the contractor respectively. The surveys investigated the impact of the breakdown repair and maintenance communication facilitated and managed by a call centre for 196 projects forming part of a national programme in South Africa.

The data was analysed by means of general linear models and F-tests with a significance level of 0.1 . A summary of the lowest $p$ value for each of the model interactions (links) is shown near the link it represents in Figure 2. The findings of Turner and Müller (2004) which were supported by the empirical results of this study are summarised in Table 2 . The results of this study are not generalized to the entire population but are stated as results from the

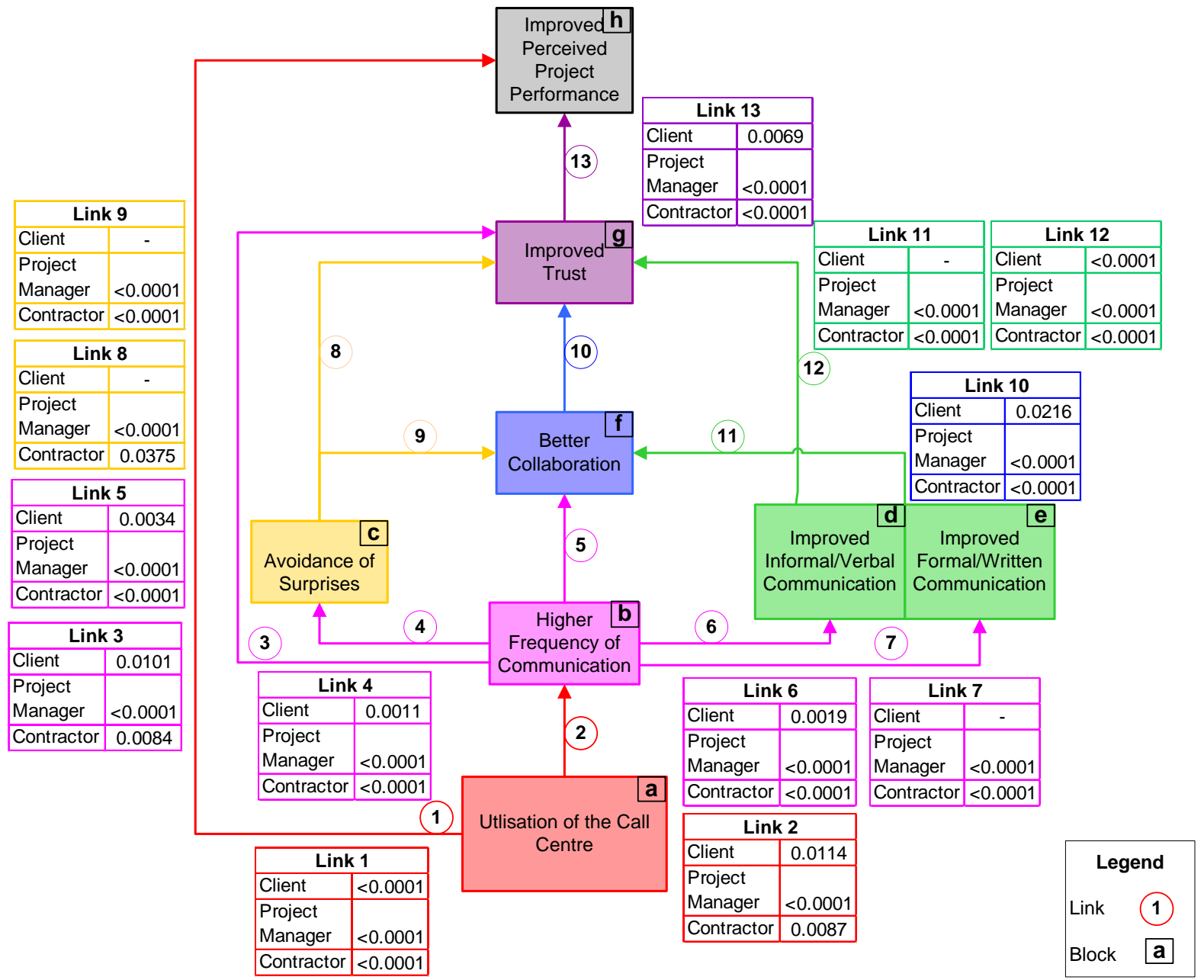

Figure 2. Significance of model interactions 
Table 2. The validity of Turner and Müller's (2004) statements with respect to the findings of this study

\begin{tabular}{|c|c|c|c|}
\hline \multirow[b]{2}{*}{ Turner and Müller (2004) Finding } & \multirow{2}{*}{$\begin{array}{l}\text { Addressed by } \\
\text { Model Link } \\
\text { No. }\end{array}$} & \multicolumn{2}{|c|}{$\begin{array}{l}\text { Valid for Principal-Agent } \\
\text { Relationship Yes/No }\end{array}$} \\
\hline & & $\begin{array}{l}\text { Client - } \\
\text { Project } \\
\text { Manager }\end{array}$ & $\begin{array}{l}\text { Project } \\
\text { manager - } \\
\text { Contractor }\end{array}$ \\
\hline $\begin{array}{l}\text { The mistrust and conflict of interest which results } \\
\text { from the principal-agency relationship can be } \\
\text { reduced by communication. }\end{array}$ & 3 & Yes & Yes \\
\hline $\begin{array}{l}\text { The communication needs of project participants } \\
\text { are best served by a mixture of formal and informal } \\
\text { communication and of written and verbal } \\
\text { communication. }\end{array}$ & 5 & Yes & Yes \\
\hline Frequent communication improves collaboration. & 5 & Yes & Yes \\
\hline \multirow{3}{*}{$\begin{array}{l}\text { A major aspect of communication in to ensure the } \\
\text { avoidance of surprises. Avoidance of surprises } \\
\text { improves collaboration and builds trust. Where trust } \\
\text { is lost there is a loss of collaboration. }\end{array}$} & 4 & Yes & Yes \\
\hline & 8 & No & Yes \\
\hline & 9 & No & Yes \\
\hline \multirow{3}{*}{$\begin{array}{l}\text { Frequent informal and formal communication, } \\
\text { written and verbal, breed collaboration which } \\
\text { increases the trust the principal has in the agent } \\
\text { and improves his service delivery experience } \\
\text { (Müller, 2003). }\end{array}$} & 5 & Yes & Yes \\
\hline & 10 & Yes & Yes \\
\hline & 13 & Yes & Yes \\
\hline \multirow{2}{*}{$\begin{array}{l}\text { Regular, daily or weekly communication gives the } \\
\text { principal the greatest comfort that they are being } \\
\text { kept informed of project progress and of the } \\
\text { decisions being taken by the agent on their behalf. } \\
\text { It is this that builds the greatest trust in the agent. }\end{array}$} & 5 & Yes & Yes \\
\hline & 10 & Yes & Yes \\
\hline $\begin{array}{l}\text { Frequent communication can help build trust on a } \\
\text { project. }\end{array}$ & 3 & Yes & Yes \\
\hline $\begin{array}{l}\text { Trust usually exists where informal communication } \\
\text { is used. }\end{array}$ & 12 & Yes & Yes \\
\hline \multirow{2}{*}{$\begin{array}{l}\text { Müller (2003) found that trust as a result of the } \\
\text { frequent collaboration between client and sponsor, } \\
\text { was a topic often viewed as being of the highest } \\
\text { importance in the buyer-seller relationship. }\end{array}$} & 10 & Yes & Yes \\
\hline & 13 & Yes & Yes \\
\hline \multirow{2}{*}{$\begin{array}{l}\text { Collaboration is a key condition for high } \\
\text { performance in projects. }\end{array}$} & 10 & Yes & Yes \\
\hline & 13 & Yes & Yes \\
\hline \multirow{2}{*}{$\begin{array}{l}\text { Müller (2003) showed that high performing projects } \\
\text { are correlated with high levels of collaboration and } \\
\text { medium levels of structure. }\end{array}$} & 10 & Yes & Yes \\
\hline & 13 & Yes & Yes \\
\hline $\begin{array}{l}\text { Clients want to know that the project is being } \\
\text { undertaken in such a way as to deliver the products } \\
\text { as agreed, to appropriate functionality and quality }\end{array}$ & 13 & Yes & Yes \\
\hline
\end{tabular}




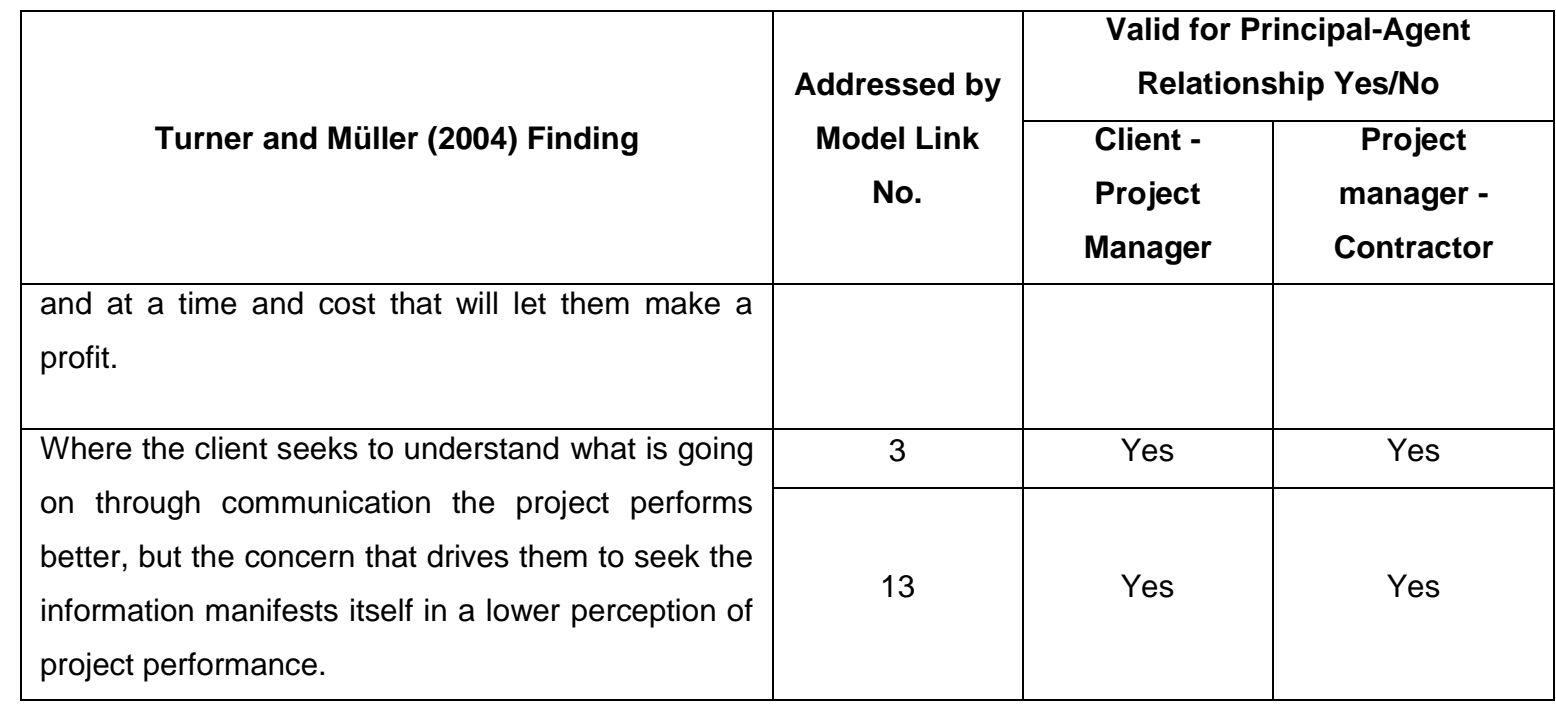

sample achieved only and provide evidence that the proposed relationship of utilising a call centre to provide frequent effective project communication and improved project performance (model links 1 and 2) was significant for both principal-agent relationships, investigated. The evidence was provided by measuring the participants' perceptions regarding the relationship between the functions performed by the call centre and the performance of the project in which they are involved. Furthermore, the proposition that frequent informal and formal communication facilitated by a call centre contributes to trust in a principal-agency relationship (model link 3) proved to be valid.

A major aspect of project communication is to ensure the avoidance of surprises or issues. Avoidance of surprises improves collaboration and builds trust. Where trust is lost there is a loss of collaboration (Turner \& Müller, 2004). The surveys indicated that frequent communication reduced the likelihood of project surprises in both principal-agent relationships but that the avoidance of surprise only contributed to collaboration in the principal-agency relationship between the project manager and the contractor $(89.5 \%$ of the project managers perceived an increase in collaboration). 
The findings of the client survey indicated that the avoidance of surprises / issues improved through frequent call centre communication. However, the avoidance of project surprises was not significant to the development of trust or collaboration between the client and the project manager in their principal-agent relationship. This finding can be attributed to the fact that the client sample group was small and due to the fact that the clients were not specifically asked in the survey whether they perceived such a correlation. The clients report all the breakdowns at the facility to the call centre; there are no breakdowns / project surprises / issues that they are unaware of.

The credibility of the contents of formal communication is high and that of informal communication is low. Formal reports are perceived by principals as the most credible source of information (Johnson, 1993). This statement by Johnson was confirmed in this study as $80.7 \%$ of project managers and $63.6 \%$ of the contractors totally agreed with the perception that they could trust the contents of the call centre's formal reports while only $68.6 \%$ of the project managers totally agreed with the perception that the contents of the call centre's informal communication could be trusted. This notion was also supported by $68.2 \%$ of the clients based on the 22 responses obtained. This finding supports the proposition that a balance of informal and formal communication is most beneficial for effective communication in a project environment.

Where the client seeks through communication to understand what is going on, the project performs better but the concern that drives them to seek the information manifests itself in a lower perception of project performance (Turner \& Müller, 2004). 64\% of the 22 client respondents (principals) who perceived that the frequent call centre communication improved the project team's communication also perceived an improvement in the project performance. $79.7 \%$ of the project managers (principals) who perceived an increase in project communication also felt that the increased communication improved the performance 
of the project. Therefore, the statement that an increase in client communication leads to a reduced perception of the project performance is disproved by the findings of this study.

The contribution of the call centre to the national repair and maintenance programme was determined by this study and it was found that $67.3 \%$ of the project managers, $61.3 \%$ of the contractors and $90.5 \%$ of the clients totally agreed with the perception that the call centre effectively manages the communication of breakdowns between the project team members. Of the project managers, contractors and clients, $73.8 \%, 52.9 \%$ and $81.3 \%$ respectively, totally agreed with the perception that the functions performed by the call centre improved the performance of the projects. The reason for the contractor's lower perception of improved project performance is due to the financial penalties which are imposed on the contractor for underperformance with regards to the timeous resolution of breakdowns logged with the call centre. Furthermore, the contractors only interaction with the call centre is the emails/faxes they receive for the breakdowns logged against their contract. The majority of each group believes that the higher frequency of communication facilitated by the call centre is responsible for an improvement in the quality (project managers $86.4 \%$, contractors $91.7 \%$ and clients $90.9 \%$ ), service delivery (project managers $91.5 \%$, contractors 91.7\% and clients 95.5\%) and customer satisfaction (project managers 100\%, contractors $83.3 \%$ and clients $95.5 \%$ ) of the project.

\section{Conclusions and Recommendations}

This study provides some interesting insight into the role that call centres can play in projects. Even though the response rate may be considered low the study provides sufficient evidence of the positive role that a call centre can play in facilitating and managing communication to aid project performance; to warrant further research in the subject. 
It is proposed that call centres can provide the correct combination of informal and formal communication to increase the communication, collaboration and trust between principals and agents in a project. Moreover; call centres can improve the client's perception of service delivery and customer satisfaction. The quality of project deliverables and the overall performance of the project can also benefit from the functions performed by a project call centre.

The results support Turner and Müller's (2004) research which states that:

- Trust exists where informal communication is used

- Frequent informal and formal communication, written and verbal, breed collaboration which increases the trust the principal has in the agent and improves his service delivery experience (Müller, 2003) and that

- Collaboration is a key condition for high performance in projects

The questions raised in this paper are answered in that it was established that the functions performed by the call centre increase the frequency of project team communication and contribute to the team's perception of project performance within the RAMP programme. Furthermore, in the study frequent call centre communication leads to the avoidance of project surprises this in turn contributes to collaboration and trust.

This study provides evidence that the RAMP Call Centre effectively facilitates and manages the repair and maintenance programme project communication and the perception of $73.8 \%$, $52.9 \%$ and $81.3 \%$ of the project managers, contractors and clients respectively is that the functions performed by the call centre improves the performance of their RAMP projects.

The study emphasizes the practical value of call centres for programmes such as the one described in this study. It is hoped that with the follow-up study it will be possible to make generalisations regarding the population and that the study will provide stronger validation 
for the model established in this paper. While this study specifically investigated the role of call centres in communication within a programme comprising of small projects, the results seem to provide some substantiation of the validity of the principal-agency theory in projects in general. It would be interesting to investigate whether the findings can be generalized to larger projects and also whether the principal-agency theory equally applies to projects where call centres are not being used.

It is proposed that further research be conducted to determine the mistrust and conflict of interest between a project's principals and agents. Furthermore, the application of call centres to projects and project communication should be investigated, as well as the utilisation of call centres for project knowledge management.

\section{References}

Akintoye, A., Shehu, Z., 2010. Major challenges to the successful implementation and practice of programme management in the construction environment: a critical analysis. International Journal of Project Management. 28, 26-39.

Axely, S., 1984. Managerial and organisational communication in terms of the conduit metaphor. Academy of Management Review, 9, 428-437.

Baguley, P., 1994. Effective Communication for Modern Businesses. McGraw-Hill, London.

Bartlett, J., 2002. Managing programmes of business change, Project Manager Today, first ed.

Bennington, L., Cummane, J., Conn, P., 2000. Customer satisfaction and call centers: an Australian study. International Journal of Service Industry Management. 11, 2, 162-173.

Bergen, M., Dutta, S., Walker, O.C., 1992. Agency relationships in marketing: a review of the implications and applications of agency and related theories. Journal of Marketing. 56, 3, 1.

Bjeirmi, B.F., Munns, A.K., 1996. The role of project management in achieving project success. International Journal of Project Management. 14, 2, 81-87.

Carlsson, B., Josephson, P.E., Larson, B., 2001. Communication in building projects: empirical results and future needs. In: CIB World Building Congress: Performance in Product and Practice, 2-6 April, Wellington, New Zealand. 
Callon, M., Latour, B., 1986. Unscrewing the big Leviathan: how actors macrostructure reality and how sociologists help them to do so. Advances in social theory and methodology: toward an integration of micro- and macro-sociologies, Boston, Routledge and Kegan Paul, 277-303.

Chen, D.N., Laing, T.P., Lin, B., 2010. An ecological model for organisational knowledge management. Journal of Computer Information Systems. 5, 3, 11-21.

Chiocchio, F., Forgues, D., Paradis, D., Iordanova, I., 2011. Teamwork in integrated design projects: understanding the effects of trust, conflict, and collaboration on performance. In: The International Research Network on Organizing by Projects (IRNOP), $10^{\text {th }}$ Ed, Montréal, Canada.

Crawford, L., England, D., Pollack, J., 2005. Uncovering the trends in project management: journal emphases over the last 10 years. International Journal of Project Management. 24, 175-184.

Crome, M., 1998. Call centers: battery farming or free range? Industrial and Commercial Training. 30, $4,137-141$.

Dainty, A., Moore, D., Murray, M., 2006. Communication in Construction: Theory and Practice. Taylor \& Francis, London.

de Coning, C., Günther, S., 2009. Programme management as a vehicle for integrated service delivery in the South African public sector. Africanus, 39, 2, 44-53.

Department of Public Works, 2004. Public servants of the year awards: inspiring success in leadership 2004. Nomination prepared by SD Phillips, Institute for Public Finance and Auditing, Pretoria.

DPW see Department of Public Works

Emmitt, S., Gorse, C.A., 2003. Construction Communication. Blackwell, Oxford.

Foulger, D., 2002a. Roles in Media. In: National Communication Association Summer Conference, May.

Foulger, D., 2004. Models of the communication process. Retrieved from: http://evolutionary media.com/papers/htm.

Gorse, C.A., Emmitt, S., Lowis, M., 1999. Problem solving and appropriate communication medium, In: Association for Researchers for Construction Management (ARCOM), $15^{\text {th }}$ Annual Conference, Liverpool, John Moores University. 1, 511-517.

Jensen, M.C. 2000. The theory of the firm: governance, residual claims and organisational forms. Harvard University Press. Cambridge, MA. 
Johnson, J.D., 1993. Organisational communication structure, Ablex Publishing, Norwood, New Jersey.

Katz, E., 1957. The two-step flow of communication. Public Opinion Quarterly, 21, 61-78.

Katz, R., 1982. The effects of group longevity on project communication and performance. Administrative Science Quarterly, 31, 241-244.

Katz, R., Tushman, M., 1979. Communication patterns, project performance, and task characteristics: an empirical evaluation and integration in an R\&D setting. Organisational Behaviour and Human Performance. 23, 139-162.

Kloppenborg, T.J. Opfer, W.A., 2002. The current state of project management research: trends, interpretations, and predictions. Project Management Journal. 33, 2, 5-18.

Koh, S.C.L., Gunasekaran, A., Thomas, A., Arunachalam, S., 2005. The application of knowledge management in call centres. Journal of Knowledge Management. 9, 4, 56-69.

Kozlowski, S. J., Bell, B. S., 2003. Work groups and teams in organizations. In Borman, W.C., Ilgen, D.R., Klimoski, R.J., Weiner, I.B. (Eds), Handbook of Psychology: Industrial and Organizational Psychology. 12, 333-375, London, Wiley.

Lehmann, V., 2009. Communication and project management: seeds for a new conceptual approach. In: Administrative Sciences Association of Canada (ASAC), Ontario, Canada.

lePine, J. A., Piccolo, R. F., Jackson, C. L., Mathieu, J. E., Saul, J. R., 2008. A meta-analysis of teamwork processes: tests of a multidimensional model and relationships with team effectiveness criteria. Personnel Psychology, 61, 273-307.

Lewis, J.P., 2001. Fundamentals of project management. American Management Association, USA. Loosemore, M., 2000. Construction crisis management. American Society of Civil Engineers, New York.

Mintzberg, H., Raisinghani, D., Theorot, A., 1976. The structure of unstructured decision process. Administrative Science Quarterly, 21, 246-274.

Mitchell, P.J., 1998. Aligning customer call centers for 2001. Telemarketing \& Call Center Solutions. $16,10,64-69$

Morand, D.A., 1995. The role of behavioural formality and informality in the enactment of bureaucratic versus organic organisations. Academy of Management Review. 20, 4, 831. 
Müller, R., Turner, J.R., 2001. The impact of performance in project management knowledge areas on earned value results in information technology projects. International Journal of Project Management. $7,1$.

Müller R. Communication of information technology project sponsors and managers in buyer-seller relationships. DBA Thesis, Brunel University/Henley Management College, UK, Henley-on- Thames, UK, 2003.

Müller, R., Turner, J.R., 2007. Matching the project manager's leadership style to project type. International Journal of Project Management. 25, 21-32.

Müller, R., Turner, J.R., 2010. Leadership competency profiles of successful project managers. International Journal of Project Management. 28, 437-448.

Mullins, L.J., 1999. The nature of organisations. Management and Organisation Behaviour, fifth ed., Financial Times Management, London.

Parr, T., Williams, D., 2006. Enterprise programme management: delivering value, Palgrave Macmillian, New York.

Pinto, M.B., Pinto, J.K., 1990. Project team communication and cross-functional cooperation in new program development. Journal of Product Innovation Management. 7, 200-212.

PMI 2008, A Guide to the project management body of knowledge, fourth ed. Project Management Institute, Newton Square, PA.

Reiss, G., 2003. Programme management demystified: managing multiple projects successfully, Spoon Press.

Shannon, C.E., 1948. A mathematical theory of communication. The Bell System Technical Journal. $27,379-423$ \& 623-656.

Shao, J., Müller, R., 2011. The development of contructs of program context and program success: a qualitative study. International Journal of Project Management.

Souder, W.E., 1981. Disharmony between R\&D and marketing. Industrial Marketing Management. 10, 67-73.

Stohl, C., 1995. Organisational communication: connectedness in action, Sage, Thousand Oaks, CA.

Torrington, D., Hall, L., 1998. Human Resource Management. fourth ed. Prentice Hall, London.

Torrington, D., Weightman, J., Johns, K., 1995. Management Methods. IPM, London. 
Turner, J.R., Müller, R., 2004. Communication and co-operation on projects between the project owner as principal and the project manager as agent. European Management Journal. 22, 3, 327336.

Tyler, T. R., 2003. Trust within organisations. Personnel Review, 32, 556-568.

Vaananen, M., Belt, P., 2010. Enhancing high-tech product development through communication. International Journal of Management and Enterprise Development, 9, 4, 405-419.

Weaver, W., 1949. The mathematical theory of communication, University of Illinois Press.

Webber, S.S., 2008. Blending service provider-client project teams to achieve client trust: implications for project team trust, cohesion and performance. Project Management Journal. 39, 2.

Weiss, J.W., Wysocki, R.K., 2000. 5-phase project management. Perseus Books, USA.

Wiener, N., 1950. Cybernétique et société, Sciences de l'Information et de la Communication, Paris. pp $442-454$ 